\title{
RELÉS ELECTROMAGNÉTICOS Y ELECTRÓNICOS. PARTE I: RELÉS Y CONTACTORES
}

\section{ELECTROMAGNETIC AND ELECTRONIC RELAYS. PART I: RELAYS AND CONTACTORS}

Arturo Pérez París: Universidad de Alcalá de Henares. Madrid (España). arturo.perez@mixmail.com

\section{CURRÍCULUM VITAE}

Profesor de la Escuela Politécnica de la Universidad de Alcalá de Henares. Ingeniero electrónico y literato. Destacan sus estudios sobre aplicaciones eléctricas y motricidad sobre los que ha publicado varios artículos científicos.

\section{RESUMEN}

Los relés son los dispositivos destinados a producir determinadas modificaciones, cuando se cumplen ciertas condiciones en un circuito eléctrico que influyen sobre él, en el mismo circuito o en otro distinto. El circuito sobre el que actúa el relé sirve de control o de señalización. Es el mundo de los automatismos industriales. En este artículo nos ceñiremos a los relés electromecánicos y a los circuitos electrónicos que, por extensión, se han dado en llamar interruptores o relés electrónicos. Un relé electromagnético como aquél interruptor mandado a distancia, que vuelve a la posición de reposo cuando la fuerza de accionamiento deja de actuar sobre él. 


\title{
PALABRAS CLAVE
}

Relé - Dispositivo - Circuito eléctrico

\begin{abstract}
The relays are devices designed to produce certain modifications, when certain conditions in an electrical circuit that influence him in the same circuit or in another. The circuit acts on the relay acts as a control or signaling. Is the world of industrial automation systems. In this article we will restrict ourselves to the electromechanical relays and electronic circuits, by extension, have been called electronic switches or relays. An electromagnetic relay as one remote control switch, which returns to the idle position when the actuating force ceases to act on it.
\end{abstract}

\section{KEY WORDS}

Relay - Device - Electrical Circuit

\section{TEXTO:}

Desde que terminé mis estudios de Telecomunicaciones, algunos nuevos campos he ido descubriendo en el amplio mundo de la electricidad y de la electrónica. Un campo que me sorprendió mucho es el de los automatismos industriales, a saber, relés de todo tipo, contactores, etc. En el presente artículo, dividido en dos partes, pretendo realizar una humilde introducción a estos elementos. Como en anteriores escritos, quisiera poner de manifiesto que está orientado a lectores con ciertos conocimientos, no muchos por cierto, pero sí algunos. Empecemos entonces. 
La norma UNE define al relé como el dispositivo destinado a producir determinadas modificaciones, cuando se cumplen ciertas condiciones en un circuito eléctrico que influyen sobre él, en el mismo circuito o en otro distinto. El circuito sobre el que actúa el relé sirve de control o de señalización.

Muchos son los dispositivos eléctricos que cumplen con esta definición. Desde el relé simple hasta el relé temporizado, con los mecanismos más complejos para el accionamiento de señales o el relé diferencial. En este artículo nos ceñiremos a los relés electromecánicos y a los circuitos electrónicos que, por extensión, se han dado en llamar interruptores o relés electrónicos. Al tratar los relés electromecánicos, por razones de semejanza en el funcionamiento y en su constitución, también hablaremos del contactor.

Definimos un relé electromagnético como aquél interruptor mandado a distancia, que vuelve a la posición de reposo cuando la fuerza de accionamiento deja de actuar sobre él. El mando a distancia presenta dos ventajas importantes: primero, la instalación puede efectuarse con una evidente economía, pues bastan dos hilos que unan la bobina del relé con el puesto de mando; segundo, aísla al operario de los puntos peligrosos de la instalación.

El funcionamiento se basa en la excitación de una bobina que magnetiza a un núcleo de hierro y éste a su vez atrae una armadura móvil a la cual van unidos los contactos: 


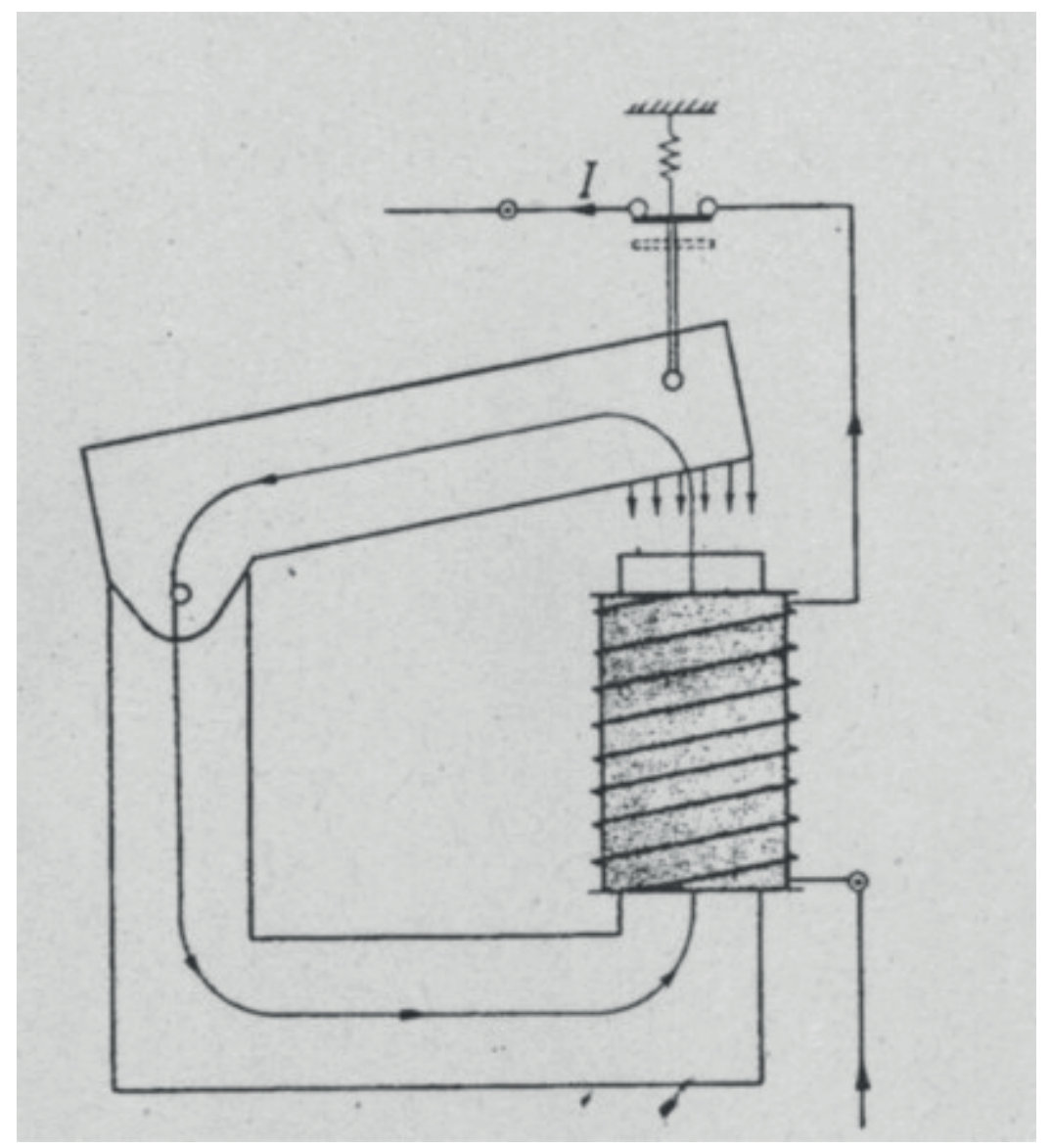

La parte de mando es el electroimán, el cual está constituido por un núcleo magnético y una bobina. El núcleo magnético está formado por chapas laminadas y aisladas entre sí cuando el relé está destinado a trabajar con corriente alterna, o es de acero macizo en caso de trabajar con corriente continua. La razón de esta diferencia se justifica diciendo que, en alterna, las corrientes de Foucault calientan el núcleo y aumentan las pérdidas; y un modo de evitar parte de estas pérdidas es usando chapas laminadas. Además, estos núcleos deben poseer la propiedad de tener bajo poder coercitivo, con el fin de no retener la parte móvil del electroimán, llamada armadura, cuando haya cesado la fuerza de atracción creada por el campo de la bobina.

Otra diferencia existente entre los núcleos magnéticos, además de la ya mencionada, consiste en una espira en cortocircuito, que recibe el nombre de espira de sombra, 
que llevan los núcleos para corriente alterna. Sirve para evitar que la armadura golpee sobre el núcleo cada vez que la corriente magnetizante y el flujo correspondiente pasen por cero, dos veces cada periodo, y la armadura tienda a abrirse momentáneamente.

La espira de sombra evita este "parpadeo" (en el gremio de los "chispas" lo llaman "releteo") y sus consecuencias, debido a que, por su disposición, tal y como se aprecia en la siguientes figuras, el flujo principal induce en ella una corriente alterna y ésta, a su vez, un flujo auxiliar desfasado del principal $120^{\circ}$, de manera que, cuando el flujo principal pasa por cero, el auxiliar tiene un valor tal que evita que la armadura se abra.

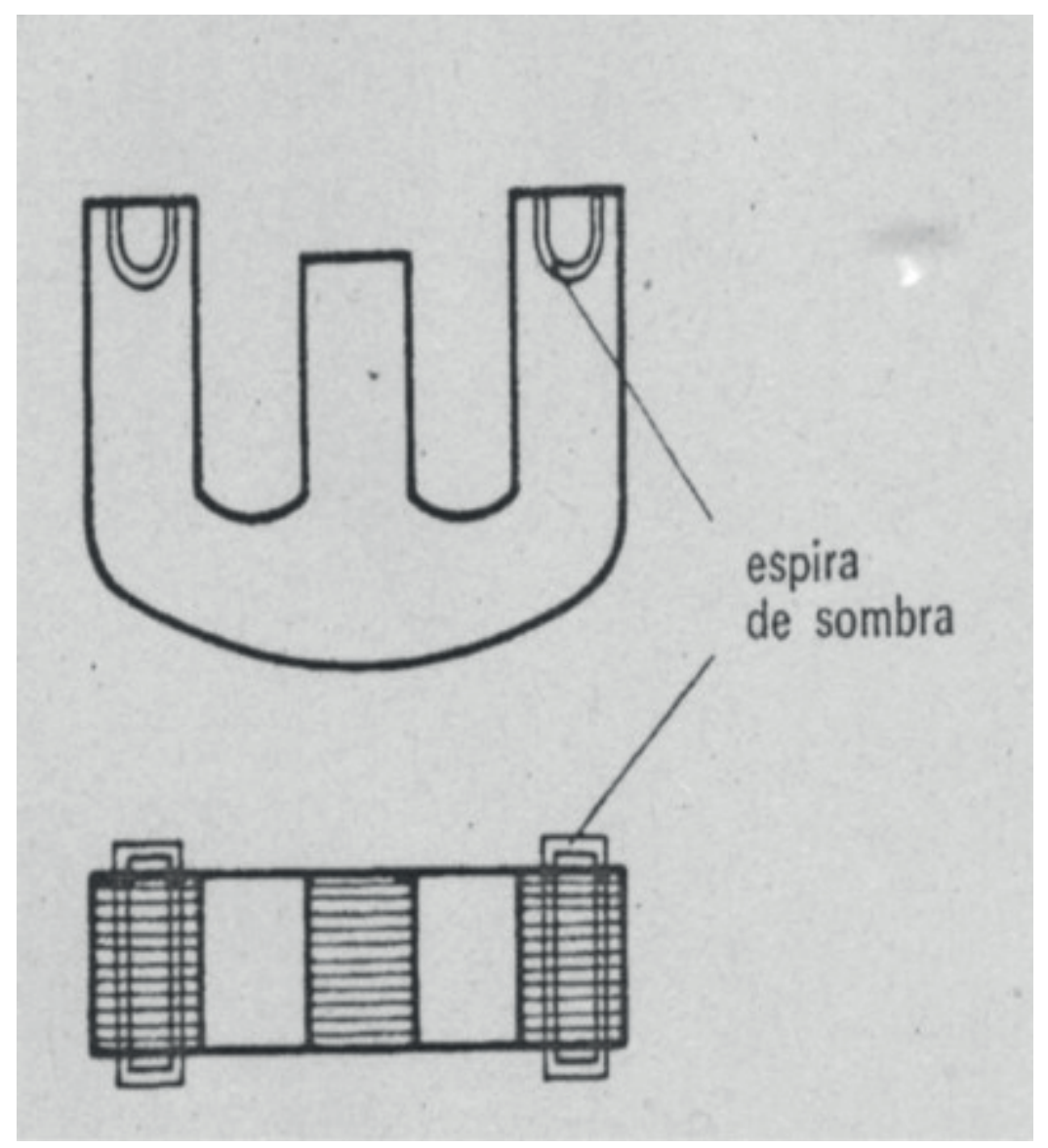




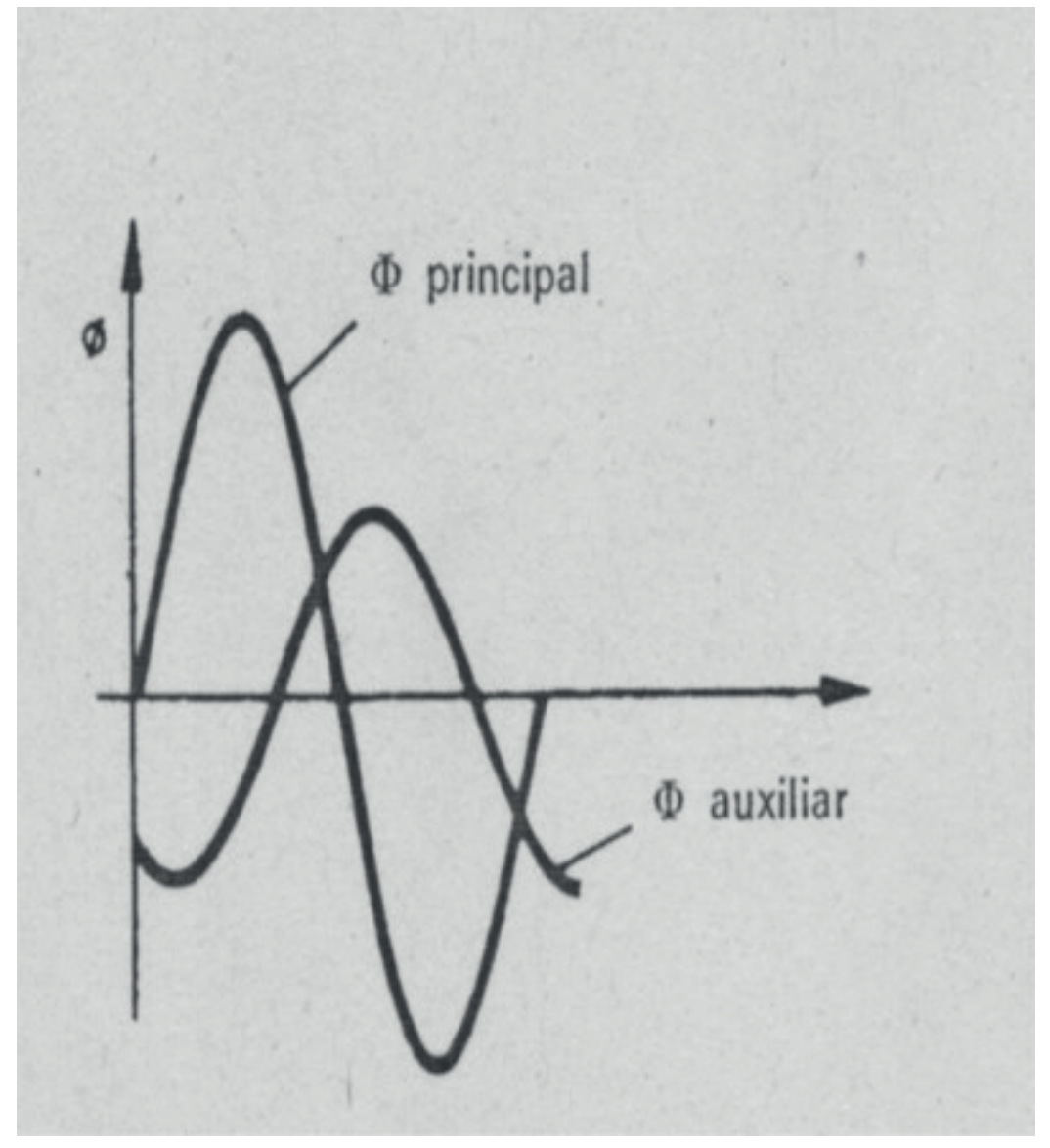

Cuando cesa la corriente de excitación de la bobina, un muelle a tal efecto empuja la armadura en sentido opuesto y ésta vuelve a su posición de reposo.

La bobina va devanada sobre un carrete de baquelita o material termoplástico y está formada por varias capas de hilo de cobre electrolítico aislado con esmalte. Una vez realizado el devanado, se somete a ensayos de calentamiento y sobre tensión, ya que del correcto funcionamiento de la bobina dependerá, consecuentemente, el del relé. Para mayor seguridad de funcionamiento, suelen calcularse de manera que, aun con tensiones del $10 \%$ por encima y por debajo del valor nominal, el accionamiento sea correcto.

En cuanto al comportamiento, se aprecian grandes diferencias según se alimenten con corriente continua o alterna. Alimentadas con corriente continua, la oposición 
sólo se debe al valor de la resistencia óhmica, debiendo por ello poseer muchas espiras y ser de hilo fino. Cuando se usan en alterna, la corriente absorbida no depende sólo de la resistencia óhmica sino también de la reactancia. En posición de reposo, la reactancia del electroimán es baja, ya que el entrehierro es grande; como consecuencia, la bobina absorbe una gran intensidad de corriente en la conexión. Cuando la estructura magnética se cierra, la reactancia aumenta y la intensidad de corriente disminuye hasta su valor nominal. Por esta razón, la bobina para alterna se construye con hilo más grueso y menos espiras que la bobina para continua. Ahora bien, si por cualquier circunstancia el cierre no es perfecto, la corriente por la bobina es superior a la nominal, lo que puede provocar un calentamiento que la llegue a fundir. Esta, circunstancia no tiene tanta importancia en corriente continua, pues la corriente absorbida es siempre igual.

Los contactos son los elementos del relé sometidos al trabajo más duro. Además, su función, cierre o apertura de los circuitos, es precisamente la que se desea obtener del conjunto del relé. Estas dos razones obligan a los fabricantes a poner especial interés en su elaboración. Los contactos deben reunir las siguientes cualidades: alta conductividad eléctrica y térmica, pequeña resistencia al contacto, débil tendencia al soldeo, buena resistencia a la erosión producida por el arco, dureza elevada, gran resistencia mecánica y poca tendencia a formar óxidos o sulfuros, que poseen elevada resistencia eléctrica. Es difícil encontrar un material que reúna estas cualidades; por ello habrá que buscar la solución en las aleaciones. Entre las más importantes se pueden nombrar: plata-cadmio (buena conductora y elevada dureza) y plata-níquel (buena conductora y resistente al arco eléctrico). Estas dos aleaciones se usan cuando los relés realizan muchas maniobras/hora o controlan corrientes elevadas. Para poco número de maniobras, se puede usar la aleación platino-iridio.

Los relés que controlan valores pequeños pueden incluso dotarse de contactos de oro o cobre; éste último si se pretende una solución más económica. La forma de los 
contactos tiene también una importancia decisiva, sobre todo para la vida de los mismos. A primera vista, podría parecer que unos contactos planos y de gran superficie son los más adecuados; sin embargo, es preciso tener en cuenta que es imposible conseguir un perfecto paralelismo entre ambas superficies en el momento de la conexión y desconexión y ello hace que no se utilice toda ella. Dándoles forma convexa, se obtendrá una superficie menor; pero, a igual fuerza, la presión será mayor en este caso. Por otra parte, esta forma favorece la extinción del arco, auque no lo elimine completamente. Así las cosas, contactos típicos son los que seguidamente mostramos:

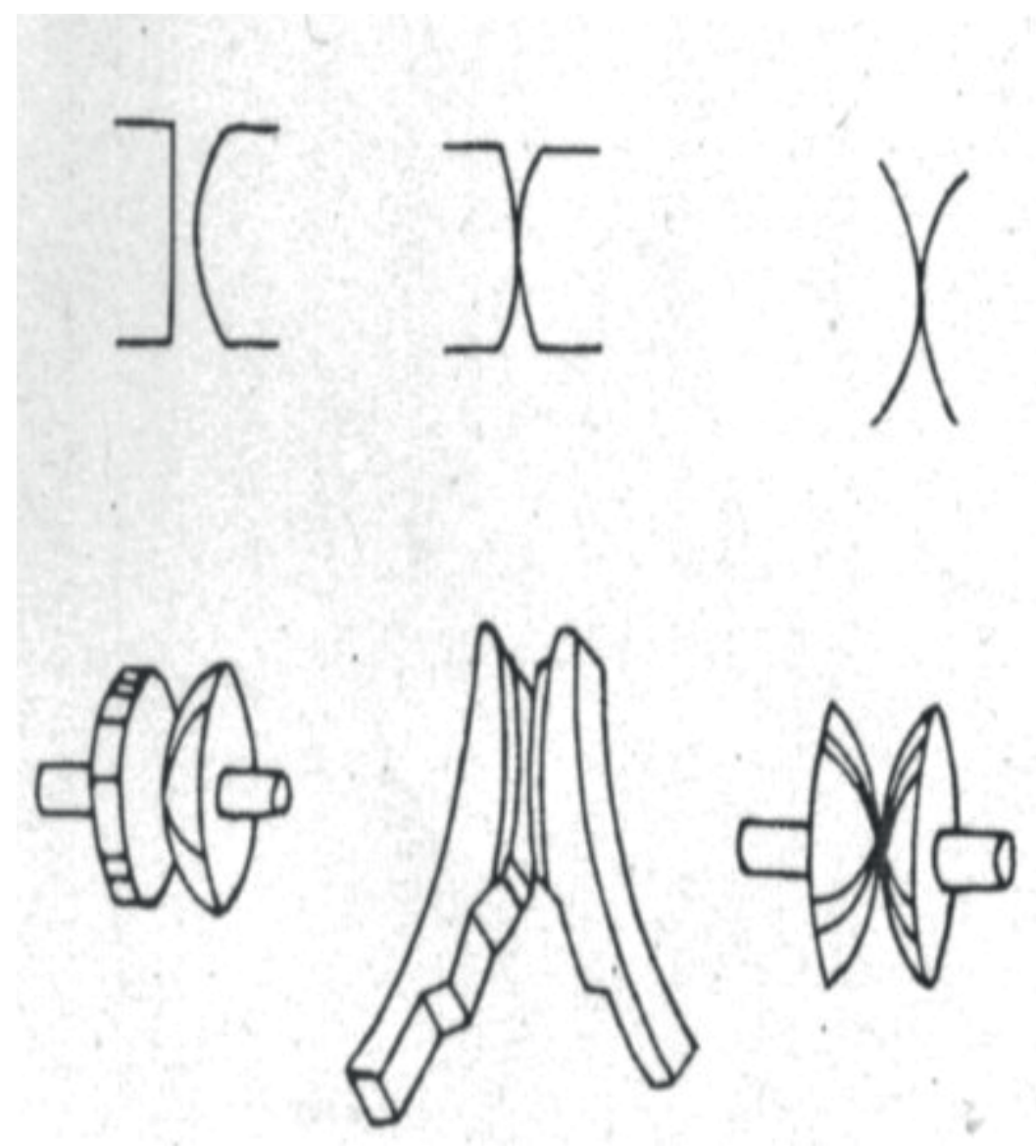

El contacto propiamente dicho va sujeto, por soldadura, a una laminilla de alpaca o bronce de poco espesor y cuya forma depende del modelo del relé. La fijación de estas laminillas es tal que van aisladas entre sí y, al tiempo, son accesibles y puede 
aumentarse su número o cambiarse por otras según las necesidades. La armadura del relé mediante algún sistema mecánico desplaza estas laminillas hasta un tope, que está colocado a más distancia que la que separa los contactos, con el fin de asegurar la buena unión de éstos. Como de su estado depende la función eléctrica que se pretendía del relé, su conservación es importante; de ahí que sea recomendable su limpieza o, incluso, si hiciera falta la reposición del relé entero.

La definición dada para el relé puede servir igualmente para el contactor. Su funcionamiento está basado en el mismo principio. Las diferencias radican en los valores eléctricos que se manejan con uno y otro dispositivo. El contactor está pensado para trabajar como interruptor automático, con corrientes y tensiones más elevadas. De hecho, va provisto de tres contactos abiertos llamados principales, más robustos que los restantes $\mathrm{de}_{\mathrm{i}}$ contactor. Estos contactos principales son los destinados a las maniobras del circuito de potencia de los montajes tales como alimentación de motores. El circuito electromagnético, la bobina, la espira de sombra realizan idéntica función, y la diferencia estriba en el tamaño y algún otro detalle de poca importancia. 


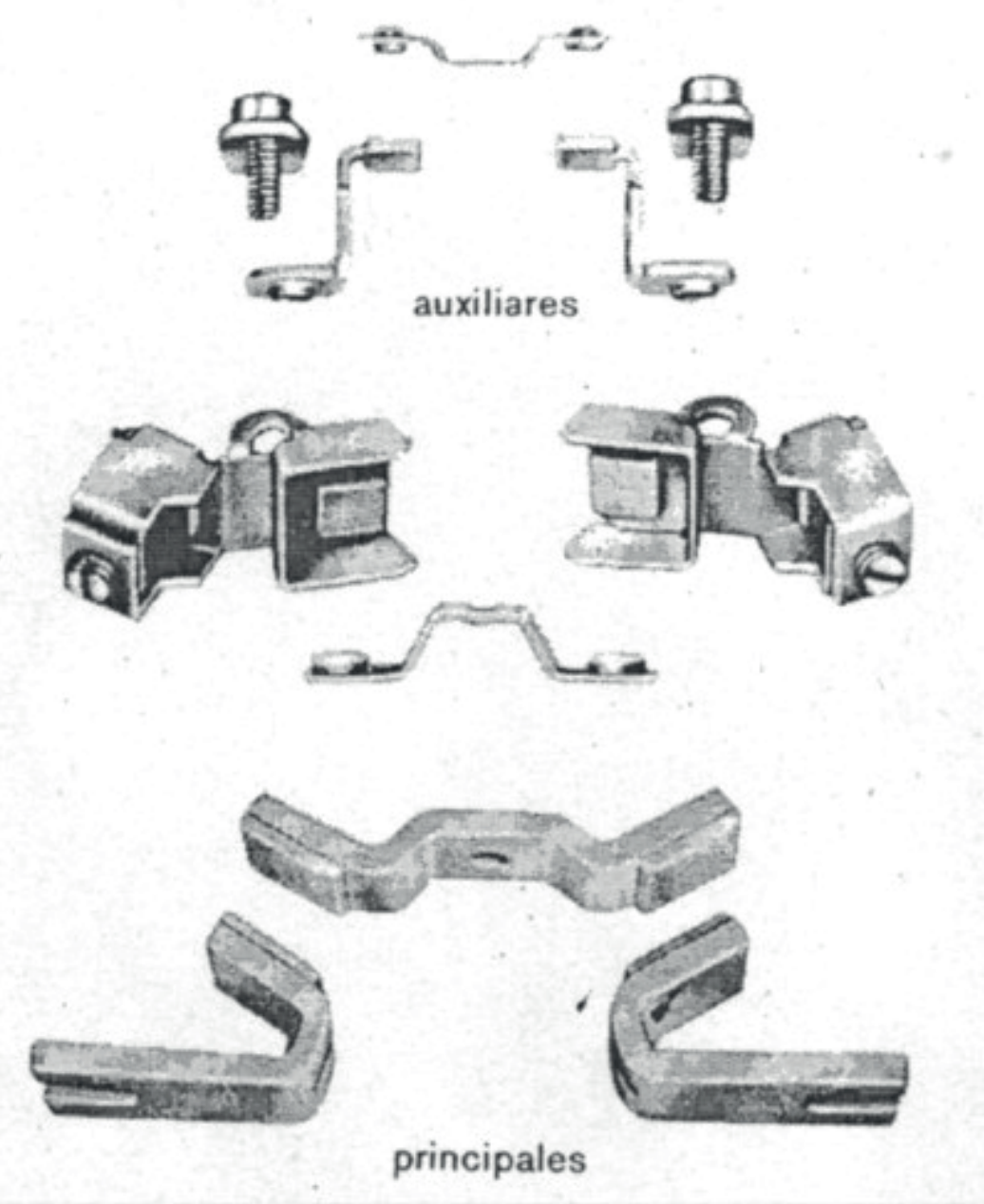

El trabajo con elevados valores de tensión y corriente hacen obligatorio dotar a los contactores con sistemas de separación entre contactos, cosa que no era necesaria en los relés. Las cámaras donde se alojan los contactos evitan la ionización del aire producida por el arco que salta entre los mismos y con ello se favorece la extinción de dicho arco, aumentando así la vida del contactor.

Los contactores de elevada potencia van dotados de un sistema de soplado por aire a presión o de soplado magnético. Esto dará idea de la importancia tan decisiva que tiene, en la vida del contactor, la extinción del arco. Desde luego, para circuitos en los 
que pueden circular hasta 250 Amperios, no es difícil imaginar el deterioro que sufrirán los contactos si no poseen alguno de los sistemas comentados.

Resumiendo, podría decirse que el soplado magnético se basa en la acción ejercida por un campo magnético que incide perpendicularmente sobre el arco, estirándolo y debilitándolo rápidamente:

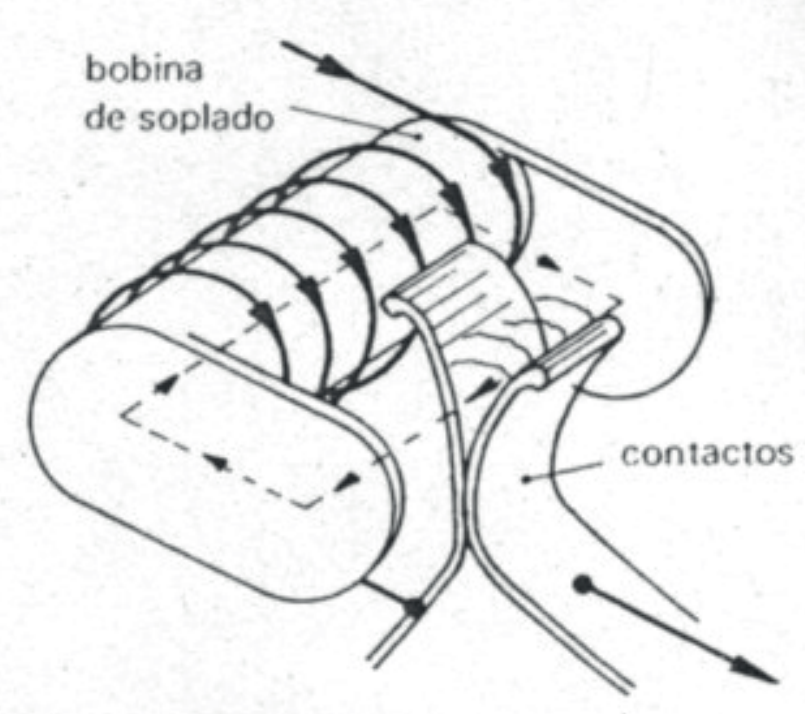

El soplado por aire a presión consiste en el envío de un chorro de aire a presión que incide perpendicularmente sobre el arco alargándolo y enfriándolo:
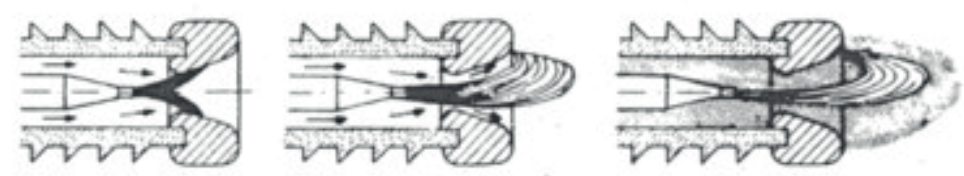

Como aplicación elemental de estos dispositivos, pero al tiempo muy empleada, tenemos el mando automático mediante pulsadores. En el circuito que a continuación se muestra, puede verse el esquema de potencia que aparecen simbolizados los 
fusibles F, los contactores D e I, el relé térmico RT y el motor, al tiempo que puede comprobarse cómo, en función del contactor accionado, cambian las fases conectadas a L1, L2 y L3 a través de los contactores.

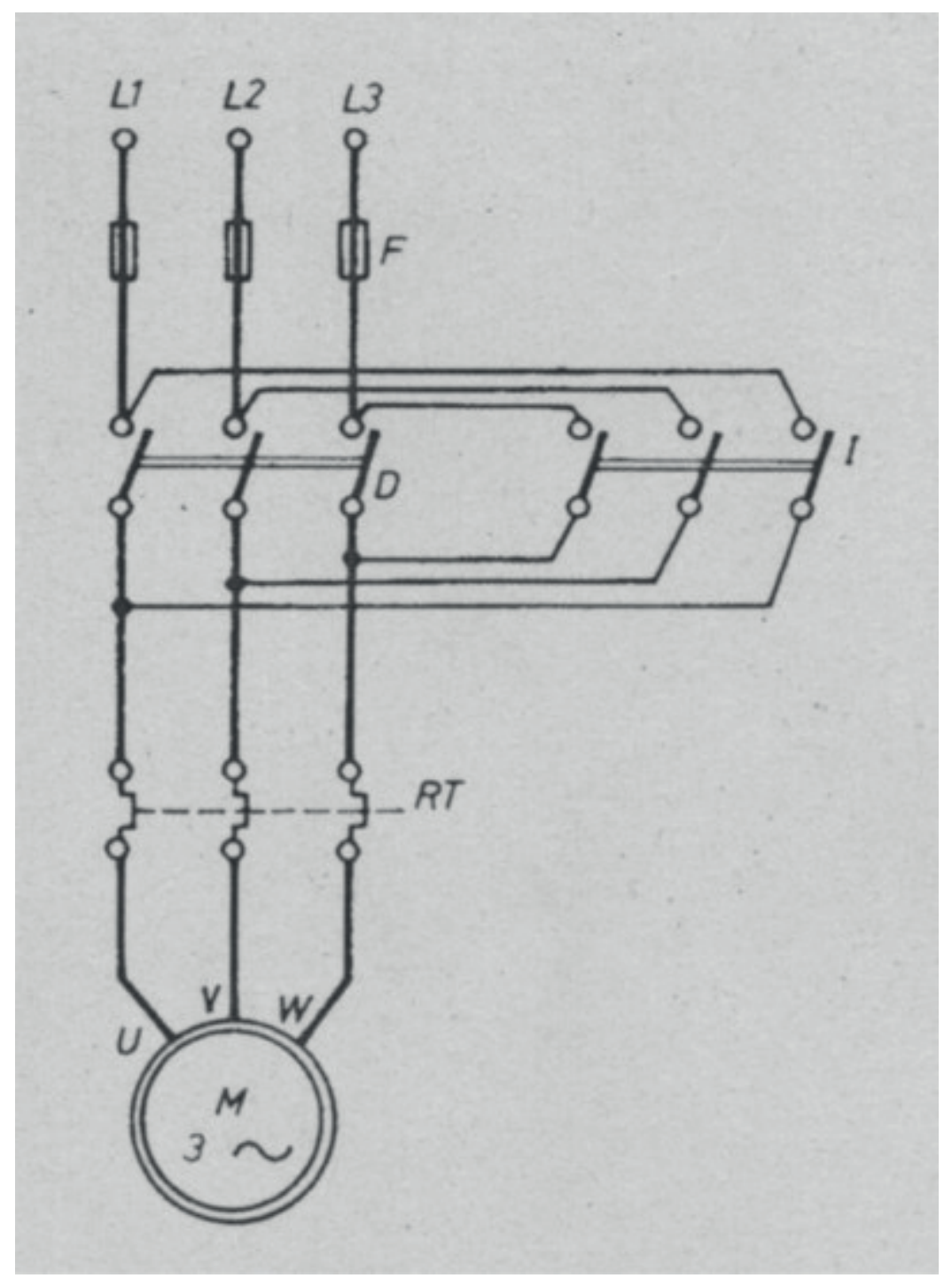

La tensión del circuito de mando se toma de las fases de alimentación; este circuito lleva su propia protección F; el accionamiento de los contactores se realiza desde los pulsadores de marcha, llevando un contacto de realimentación cada contactor, y un contacto cerrado que sirve de enclavamiento eléctrico de manera que, mientras el 
motor gira hacia la derecha, contactor D, no puede ponerse en funcionamiento el contactor del sentido izquierda, contactor 1 y viceversa.

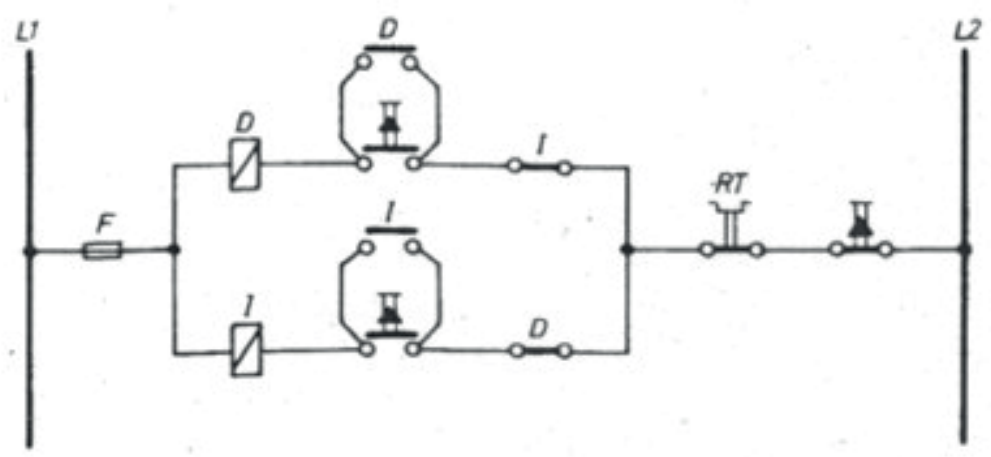

Otro tipo de relé muy empleado, sobre todo como sensor magnético es el de tipo Reed. Están constituidos por un par de láminas de baja reluctancia, ferromagnéticas, herméticamente cerradas en un tubo de vidrio lleno de un 97\% de nitrógeno y un $3 \%$ de hidrógeno a unos cuantos kp/cm2 de presión:

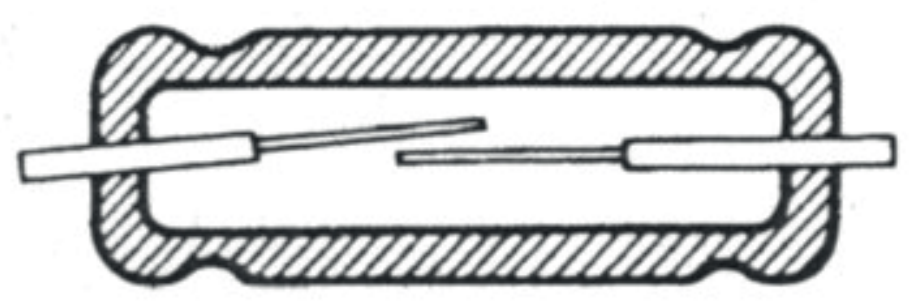

Las láminas son de níquel-hierro y, en la zona de contacto, suelen llevar un baño de oro. La potencia de conmutación puede llegar hasta 60 VA, con 220 V de tensión alterna. El número de maniobras es de varios cientos de millones, con un tiempo de reacción de $0,5 \mathrm{~ms}$. 
Al someter las láminas a la acción de un campo magnético creado por una bobina, los extremos de las láminas adquieren polaridades de distinto signo $\mathrm{y}$, cuando el flujo magnético es suficiente, las fuerzas de atracción cierran el circuito que se desea gobernar.

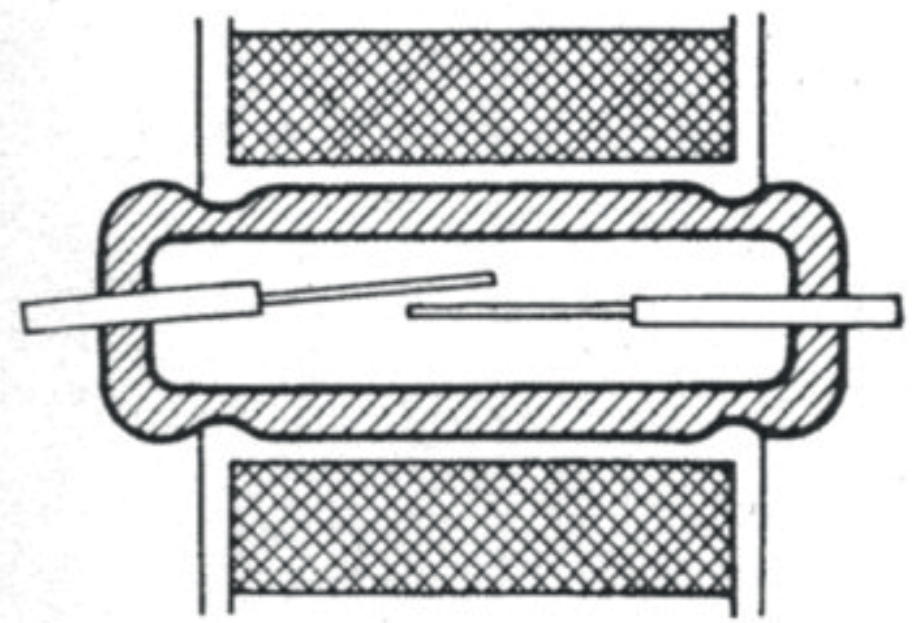

Para contactos normalmente cerrados, se dota al conjunto con un imán permanente, que mantiene cerrado el contacto. El campo que crea la bobina cuando es excitada anula la acción de imán y abre el interruptor:

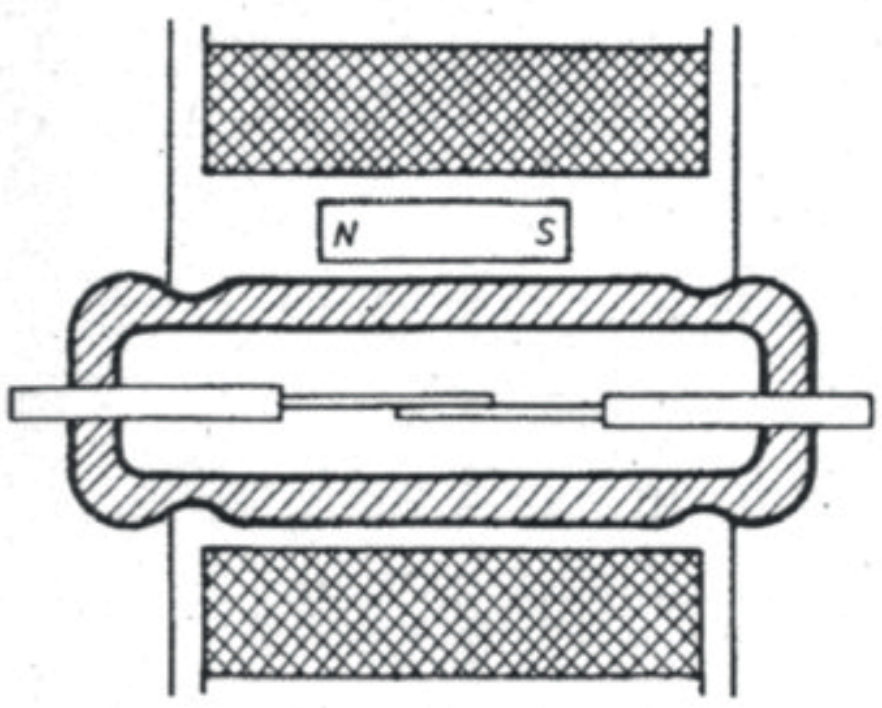


El accionamiento del relé puede realizarse mediante una bobina o un imán permanente, según las aplicaciones prácticas en las que se utilicen. La distancia a la que deben estar situados el contacto y el imán dependerá de la sensibilidad de las láminas y de la fuerza del imán. Cuando se hallen lo suficientemente próximos, el contacto normalmente abierto se cerrará. Al distanciarse el contacto volverá a la posición que ocupaba, aunque se tendrá presente que la distancia para el cierre es siempre inferior a aquélla que provoca la apertura.

Los casos más comunes son los siguientes:

a) Movimiento perpendicular. Hay una sola posición de cierre con un movimiento máximo del imán:

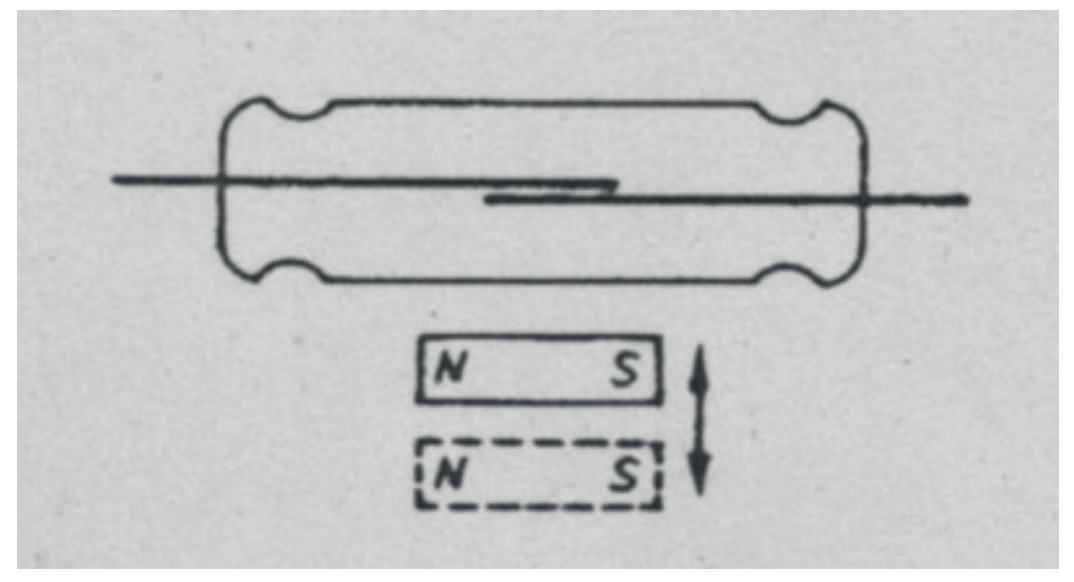

b) Movimiento paralelo. Puede haber hasta tres cierres con un movimiento máximo del imán. Se podrá conseguir un cierre con un movimiento mínimo: 


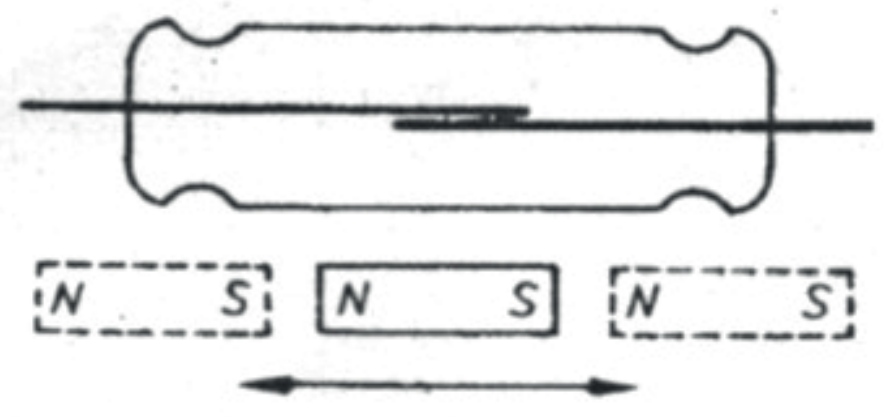

c) Movimiento de rotación. Girando el contacto o el imán perpendicularmente a su eje, se obtendrán dos cierres per vuelta. Cuando los ejes son paralelos, el interruptor está cerrado. Cuando están perpendiculares, el interruptor está abierto:

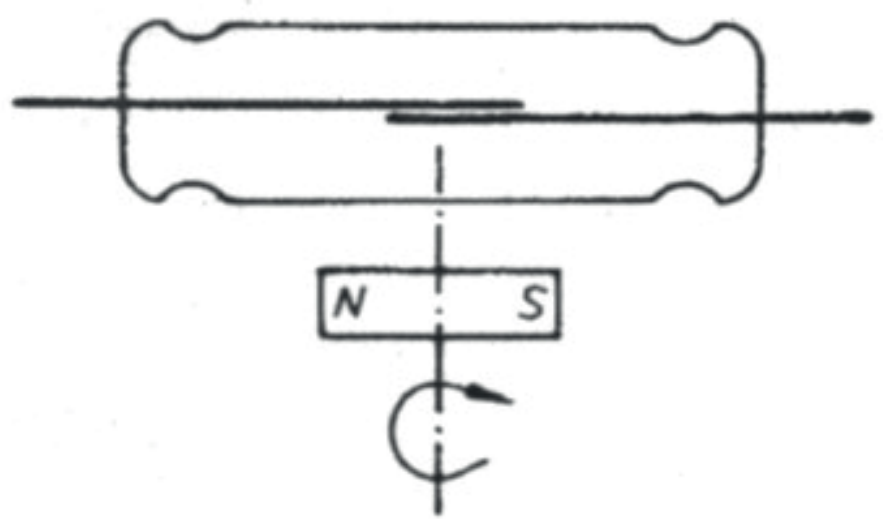

d) Movimiento pivotante. Para conseguir el cierre, el imán deberá realizar un movimiento angular considerable: 

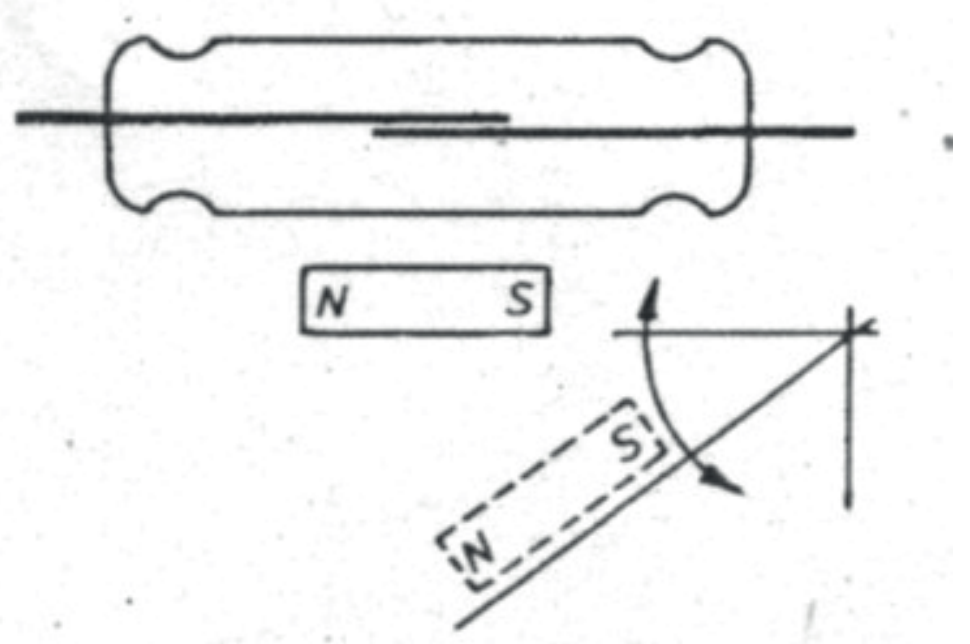

e) Pantalla. En este tipo de utilización el interruptor y el imán son fijados de una manera permanente en una posición tal que los contactos están cerrados. Una pieza de metal ferromagnético se interpone entre el imán y el interruptor para provocar la apertura, pues actúa de pantalla:

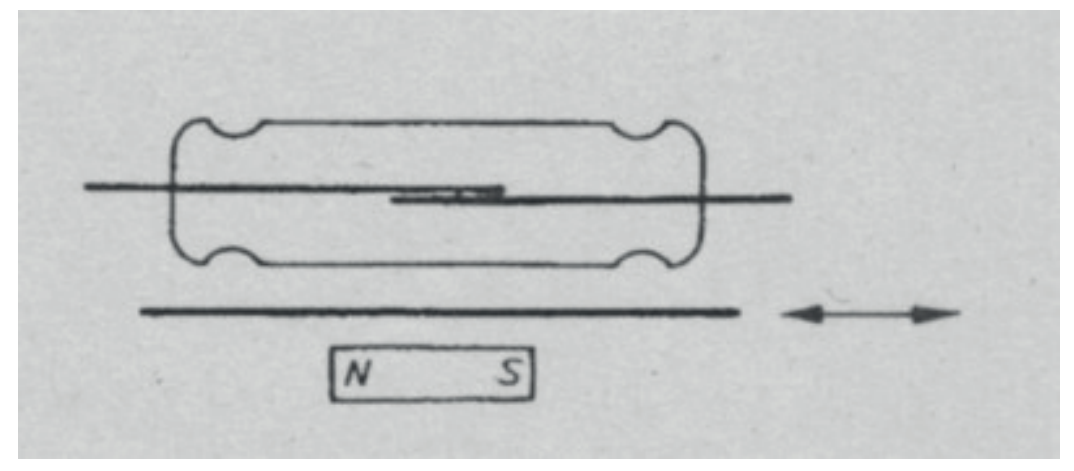

f) Polarización. La polarización creada por un imán fijo próximo al interruptor hace que éste permanezca normalmente cerrado. La aproximación de otro imán polarizado inversamente anula las líneas de fuerza y el interruptor se abre: 


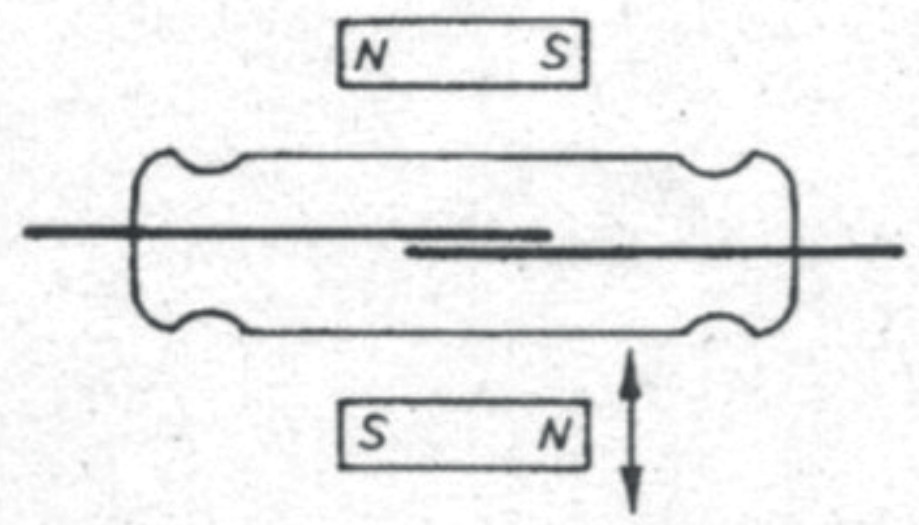

Algunos de estos casos podrían tener su aplicación en sistemas como los que a continuación se muestran, en el que el imán va fijo a una leva:

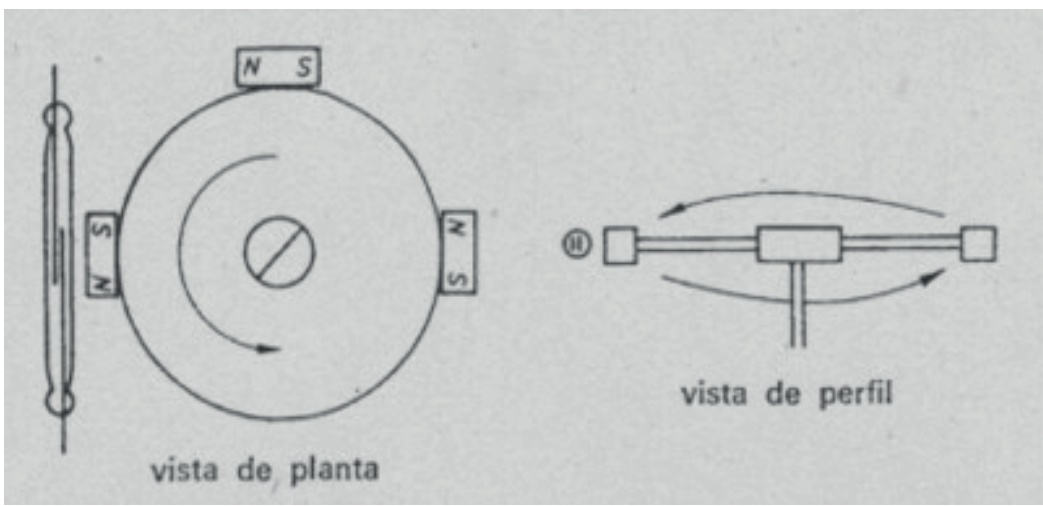

En el siguiente ejemplo se acciona por presión de aire: 


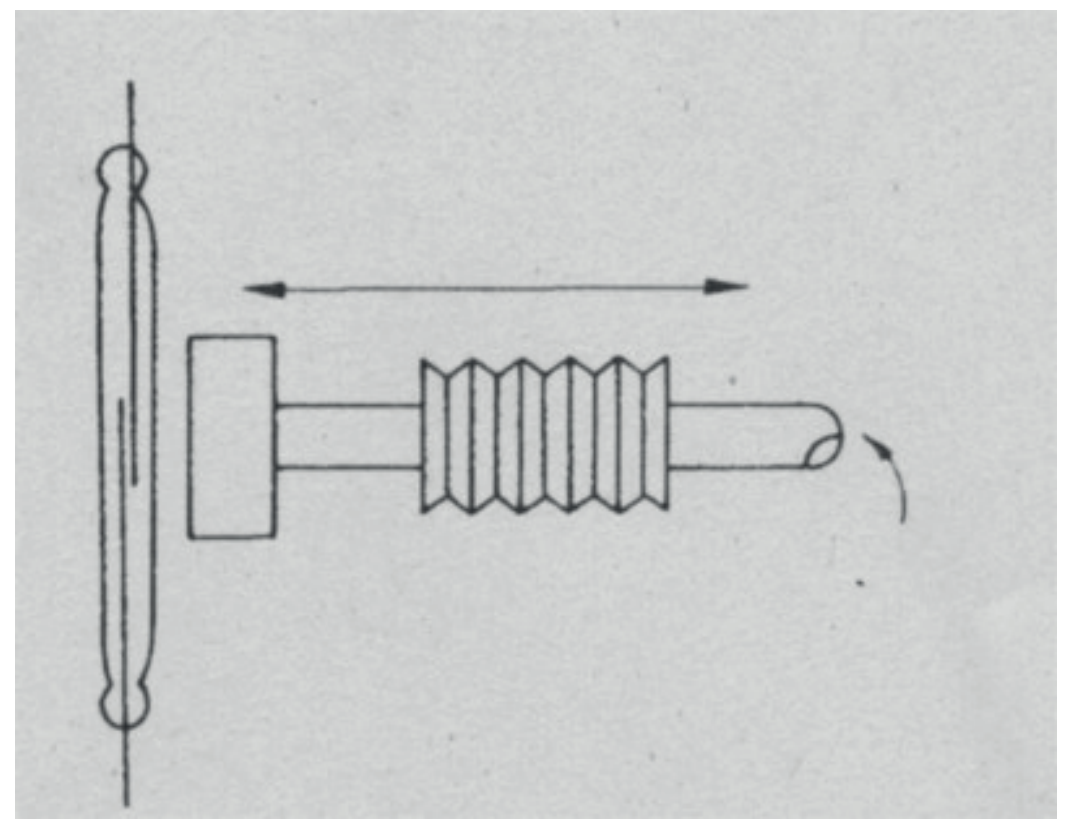

Otro podría ser por medio de un flotador:

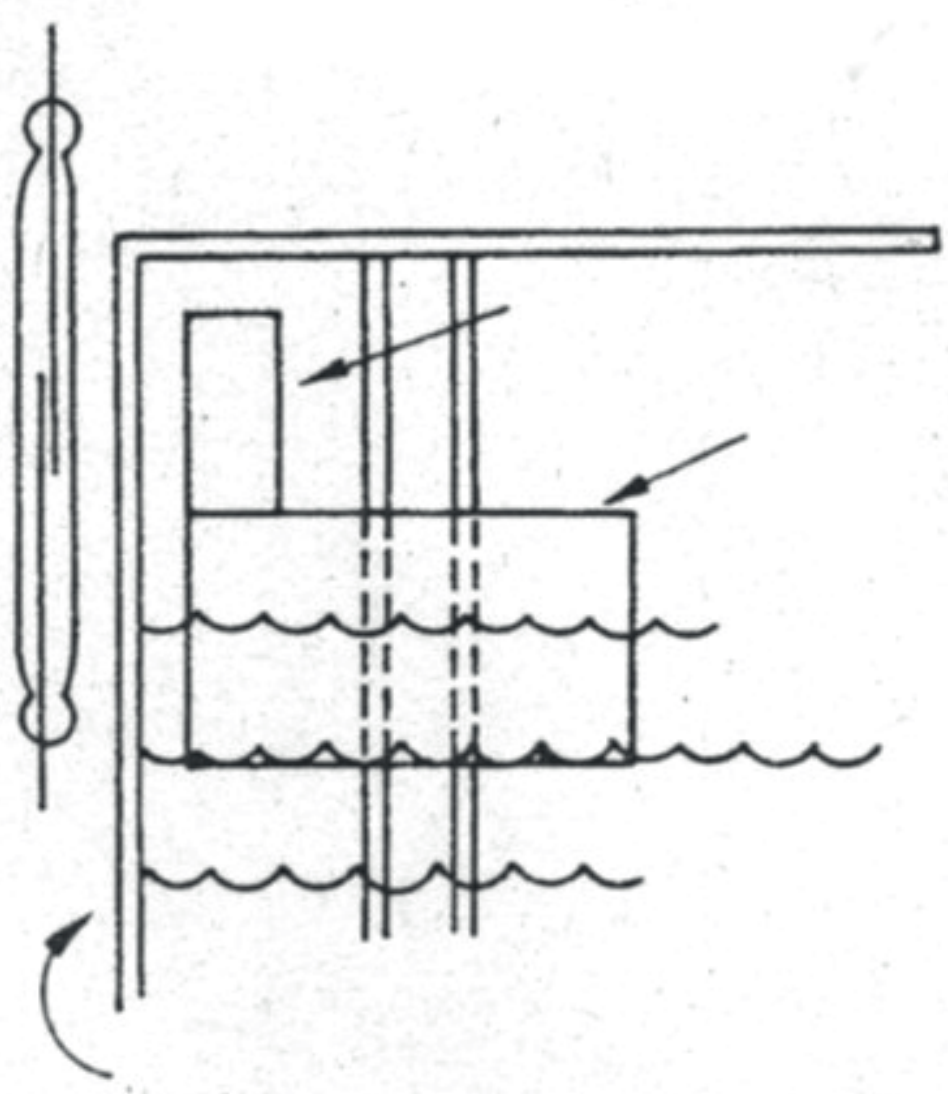


Por último, el relé se acciona al desaparecer la pantalla:

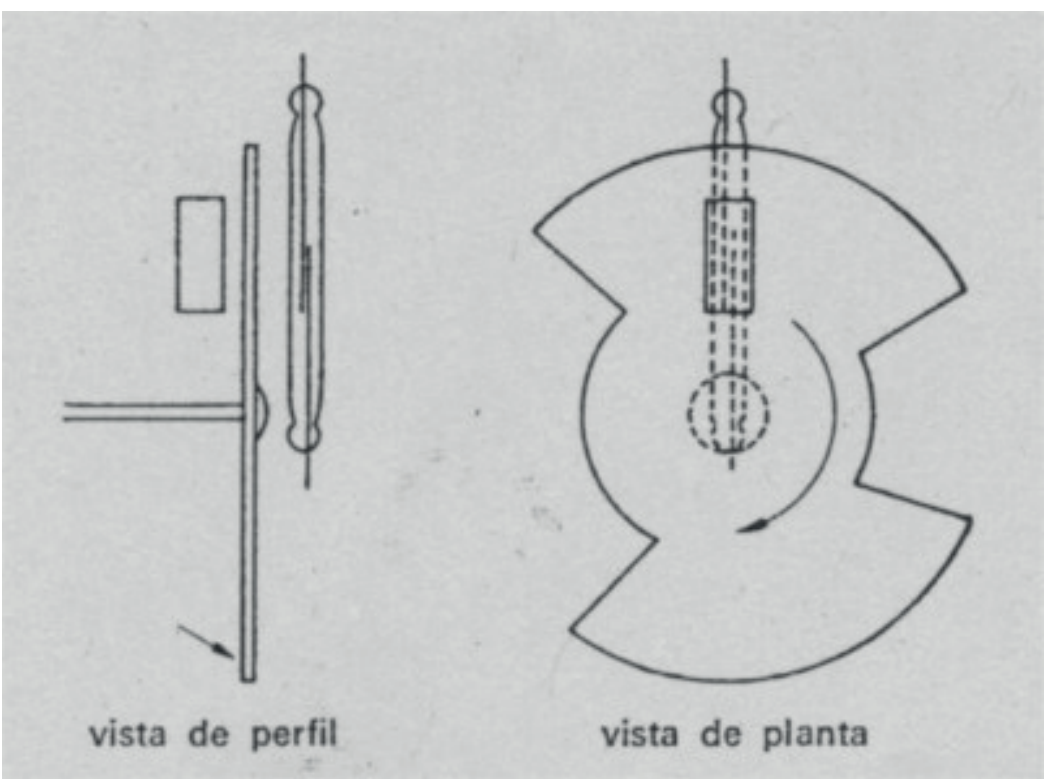

En todos estos ejemplos queda puesto de manifiesto el principal uso de este tipo de relés: como sensor magnético, capaz de controlar gran señal. Por otro lado el movimiento de proximidad con bobina, la otra manera de manejar este tipo de dispositivos, se hará básicamente de las cuatro manera básicas siguientes:

a) Contacto simple. El contacto se cierra cuando la bobina es excitada 


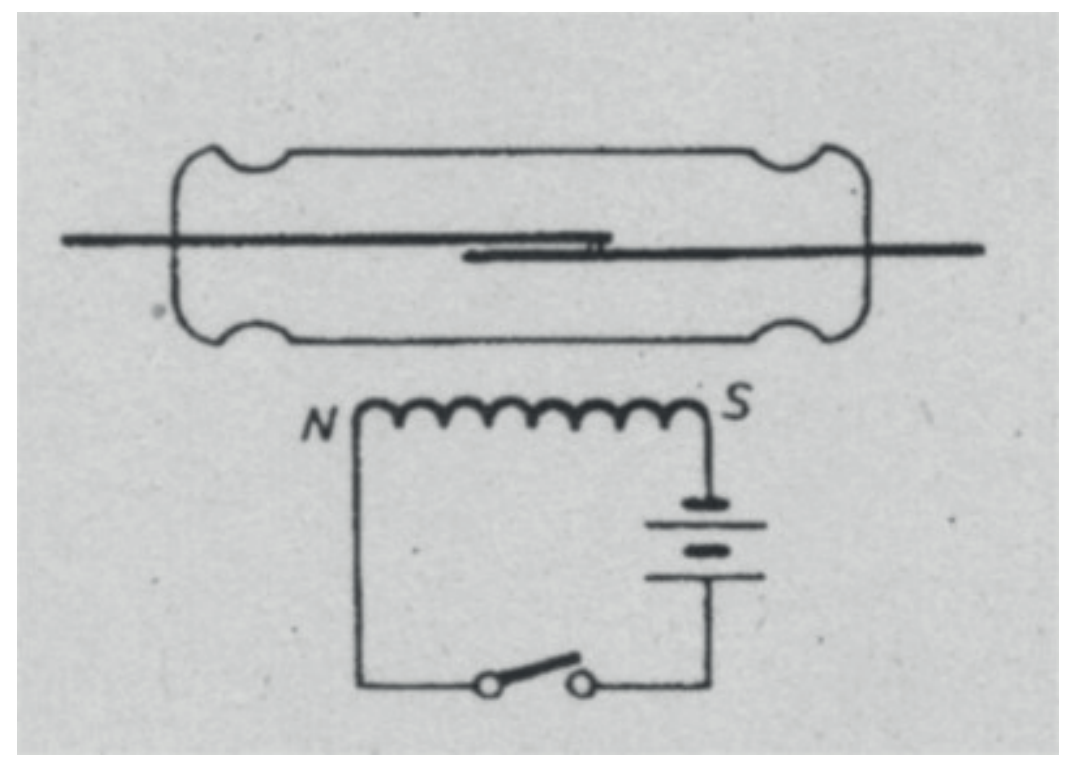

b) Cierre por impulso. La bobina A crea un campo cuyo valor es un poco inferior al que el relé necesita para el cierre. Un corto impulso en la bobina B cierra el contacto, que permanece cerrado. 


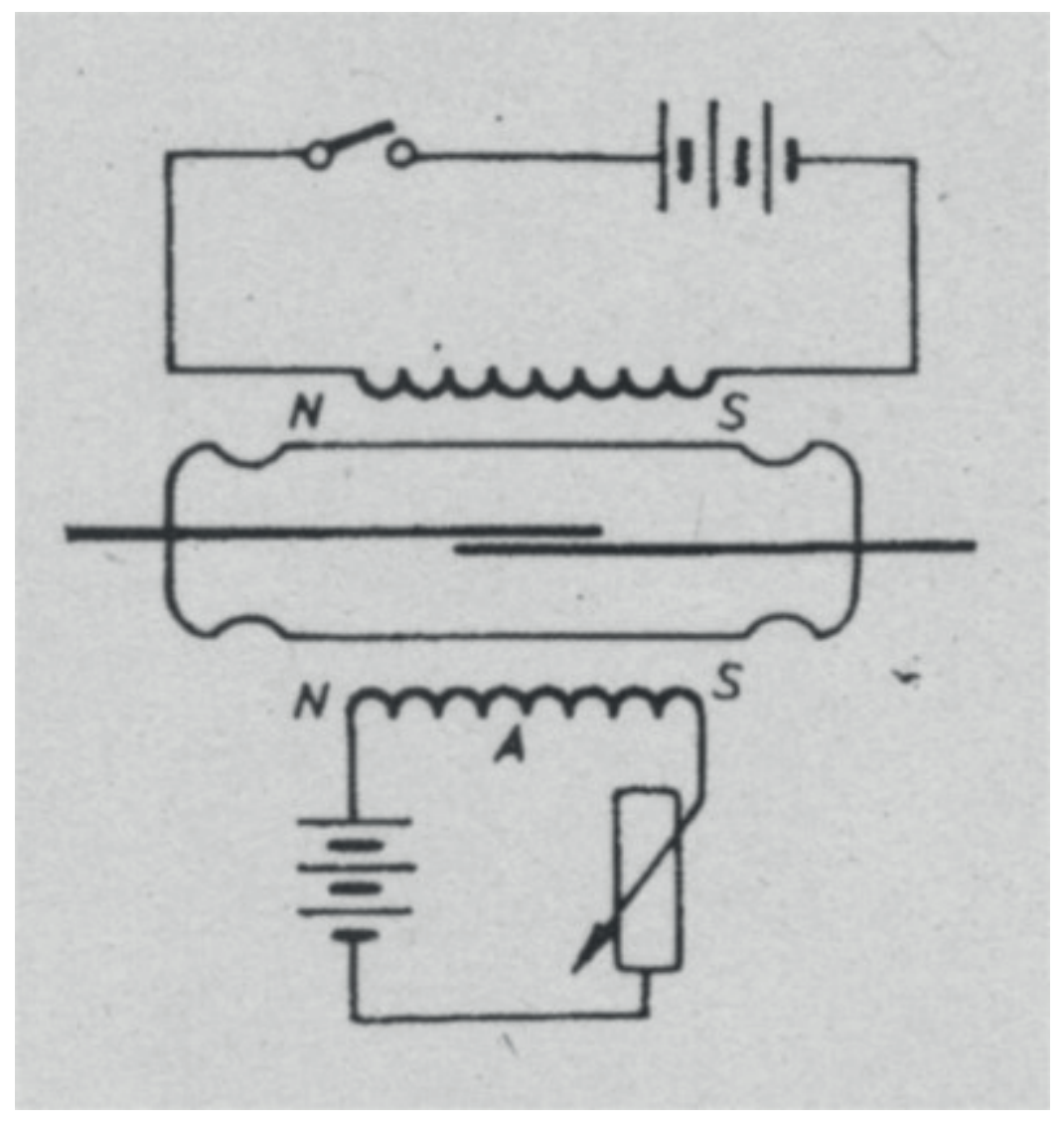

c) Apertura por bobina. El imán mantiene cerrado el contacto en ausencia de corriente en la bobina. El campo creado por la bobina al ser excitada anula el campo de imán y abre el interruptor. 


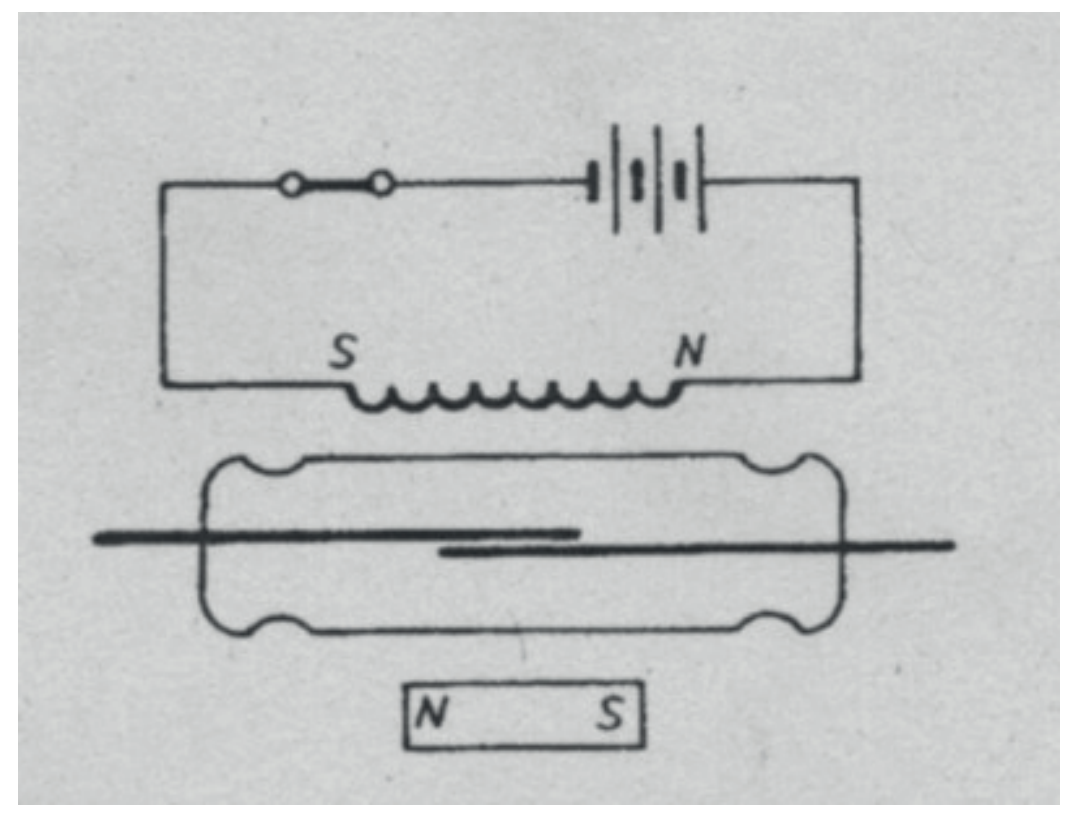

d) Diferencial. Siguiendo las polaridades respectivas de las bobinas A y B; el cierre puede hacerse para muy pequeñas o muy grandes diferencias. 


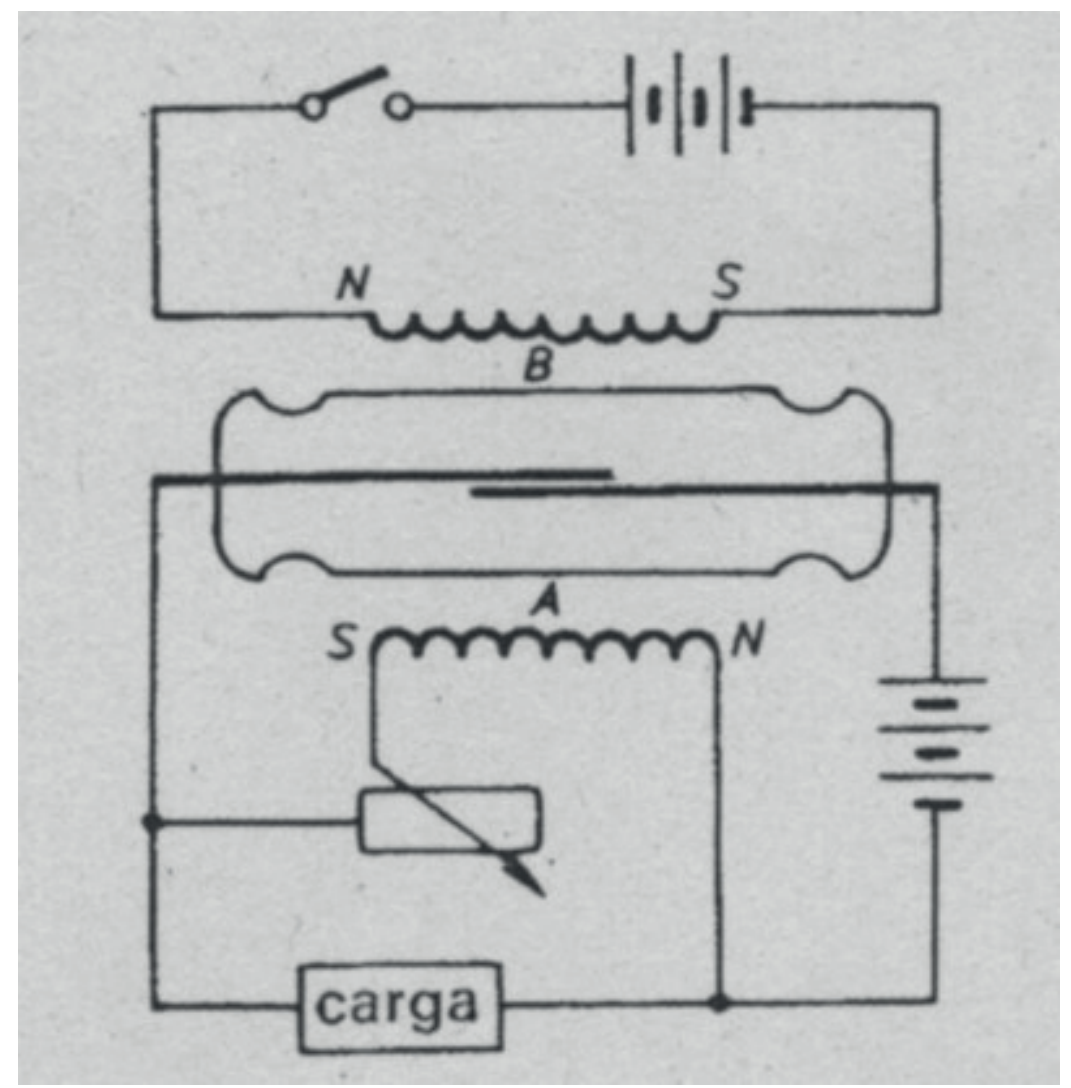

En la entrega del próximo mes, estudiaremos los interruptores electrónicos, también denominados relés electrónicos. 